\title{
Importação Paralela na União Européia
}

\author{
Renata Lucas de Casvalho
}

Advogada, Faculdade de Direito Cândido Mendes (Rio de Janeiro - 1993), Pós-graduação em Direito Empresarial pela Faculdade de Direito Cândido Mendes (Rio de Janeiro - 1995), reconhecimento para exercício da profissão (Direito Internacional) na Alemanha desde outubro de 1999.

\section{Definição}

1

mportação paralela é a venda ou dis. tribuição de um produto ou de uma prestação de serviço fora de uma área autorizada. Representa a concorrência de mercadorias e prestações de serviços, pertencentes a mesma firma, que são oferecidos no mercado nacional com preços diferentes, mas dentro de certas especificações e normas.

\section{0 problema da política de concorrência}

A União Européia (UE) tem como objetivo a constituição de um mercado comum com uma economia e moeda única, levando em consideração a diferença política dos países membros.

A política econômica da UE está ligada a uma economia de mercado aberto com livre concorrência (art. 3a, 1 e art. 102a EGV, Vertrag zur Gründung der Europäischen Gemeinschaft - Contrato da Comunidade Européia), que suprime os obstáculos prejudiciais ao comércio dentro da União Européia e cria um mercado interno para os seus cidadãos (art. 7a EGV).
A falta de barreiras internas traz como conseqüências a liberdade do tráfego de pessoas e de mercadorias, do estabelecimento de novas firmas, da prestação de serviços, e do capital entre os países-membros.

O principal problema da integração da UE consistiu em como desenvolver uma economia livre, quando o objetivo de legislar um mercado comum se contrastava com a realidade das diferentes políticas econômicas de proteção dos países membros, os quais possuíam diferentes comportamentos no mercado de empresas com relação ao regulamento dos preços.

Assim sendo, levavam ao isolamento do mercado nacional, restringindo a livre escolha do consumidor europeu e, conseqüentemente, indo em direção contrária ao desejado efeito de uma liberdade econômica.

O Contrato da Comunidade Européia tem em vista impedir a restrição da concorrência entre diferentes empresas e estimular a concorrência dentro das mesmas empresas, trazendo como conseqüên- 
cia a licença para a importação paralela. É interessante examinar os mercados nos quais a importação paralela ocorre. Nas decisões proferidas pela Comissão Européia tratam-se dos seguintes mercados: de produtos de alta tecnologia (que são entregues ao consumidor com preços altos como por exemplo os automóveis), de medicamentos, de produtos de luxo como os perfumes, artigos de moda e bebidas alcoólicas. Em todos esses casos é de se esperar nos países membros um estímulo à importação paralela dos países de preços mais baixos para países de preços superiores, dos mesmos produtos com uma considerável diferença de preço. Diferentes custos de produção ou despesas de distribuição e tipos de impostos exigidos em cada país são umas das causas da diferença de preços dentro dos países da União Européia. Exemplos são os automóveis que possuem representações divergentes na política nacional com relação a política de tráfego, de impostos ou de meio ambiente, que são responsáveis pela diferença no preço final ao consumidor. As diferenças de preços e de produtos são, em parte, uma estratégia dos empresários para a obtenção de maior lucro, como também para incentivar a atividade de pesquisa e desenvolvimento no próprio mercado interno.

\section{Legislação Européia sobre Cartel}

As normas anti-cartel da União Européia se encontram nos arts. 81 a 89 do Contrato da Comunidade Européia (EG. Vertrag). Segundo o art. 81 (EGV) é incompatível e proibido no mercado comum, todo acordo entre as empresas, decisões ou re- soluções de associações empresariais e modos de conduta votados por empresas que prejudiquem o comércio e o negócio entre os países membros como também qualquer acordo que tenha como objetivo o impedimento, a restrição ou a falsificação da concorrência dentro do mercado comum europeu.

$$
\text { "Art. } 81 \quad \text { (Verbot }
$$
we t t bewerbsbeschränkender Vereinbarungen und Verhaltensweisen) (1) Mit dem Gemeinsamen Markt unvereinbar und verboten sind alle Vereinbarungen zwischen Unternehmen, Beschlüsse

Bnternehmensvereinigungen und aufeinander abgestimmte Verhaltensweisen, welche den Handel zwischen Mitgliedstaaten zu beeinträchtigen geeignet sind und eine Verhinderung, Einschränkung des Wettbewerbs innerhalb des Gemeinsamen Marktes bezwecken oder bewirken, insbesondere

a) die unmittelbare oder mittelbare Festsetzung der An-oder Verkauftspreise oder sonstiger Geschäftsbedingungen;

b) die Einschränkung ode Kontrolle der Erzeugung, des Absatzes, der technischen Entwicklung oder der Investitionen;

c) die Aufteilung der Märkte oder Versorgungsquellen;

d) die Anwendung unterschiedlicher Bedingungen bei gleichwertigen Leistungen gegenüber Handelspartnern, wodurch diese im Wettbewerb benachteiligt werden

e) die an den Abschluß von Verträgen geknüpfte Bedingung, daß di
Vertragspartner zusätzliche Leistungen annehmen, die weder sachlich noch nach Handelsbrauch in Beziehung zum Vertragsgegenstand stehen.

(2) Die nach diesem Artikel verbotenen Vereinbarungen oder Beschlüsse sind nichtig.

(3) Die Bestimmungen des Absatzes 1 können für nicht anwendbar erklärt werden auf

- Vereinbarungen oder Gruppen von Vereinbarungen zwischen Unternehmen,

- Beschlüsse oder Gruppen von Beschlüssen

Unternehmensvereinigungen, von

- aufeinander abgestimmte Verhaltensweisen oder Gruppen von solchen, die unter angemessener Beteiligung der Verbraucher an dem entstehenden Gewinn zur Verbesserung der Warenerzeugung oder -Verteilung oder zur Förderung des technischen oder wirtschaftlichen Fortschritts beitragen, ohne daß den beteiligten Unternehmen

a) Beschränkungen auferlegt werden, die für die Verwirklichung dieser Ziele nicht unerläßlich sind, oder

b) Möglichkeiten eröffnet werden, für einen wesentlichen Teil der betreffenden Waren den Wettbewerb auszuschalten."

$\mathrm{O}$ art. 81 (EGV) assegura então a concorrência funcional sem falsificação no mercado comum e a liberdade de acesso para outros países neste mercado. A livre concorrência criada possibilita que mercadorias e prestações de serviços sejam oferecidos para o consumidor com melhores ofertas e condições.
Além disso, as empresas que se encontram em concorrência devem melhorar e inovar seus produtos para o interesse do cliente. O mesmo artigo atua expressamente contra "todos" os acordos entre as empresas que restringem essa concorrência livre. Os órgãos da comunidade compreendem como acordo o entendimento de empresas ou suas associações sobre a prática de restringir a concorrência, ou seja, todo acordo de vontade sobre sua aparição conjunta no mercado.

Com relação aos exemplos das regras dos diversos decretos e do art. 81 (EGV) podem ser acentuados especialmente os acordos sobre preços e condições, as restrições ou controle de produção, de venda, de desenvolvimento tecnológico ou investimentos, como também a distribuição nos mercados e os contratos acessórios.

A experiência nos acordos de restrições de concorrência feitos pelas empresas mostra que, não só as restrições ao comércio do estado, como também as limitações da concorrência privada, podem surtir efeito como obstáculos ao livre comércio. Deste modo as barreiras comerciais, privadas e estatais devem ser primeiramente abolidas para a criação de um mercado interno competitivo em nível internacional.

Os mais importantes casos de aplicação do art. 81, I, letra c são os amplos cartéis internacionais, as ordens de mercado nacional como também o cartel de importação e exportação. O comprador tem 0 compromisso de somente vender em uma área específica ou respeitar o nível de preço do mercado alvo e manter o acordo de realização do controle comum das merca- 
dorias na importação, como por exemplo verificar a marca de controle com o objetivo de evitar a importação paralela através de outros comerciantes.

Para restringir a possibilidade de venda dos concorrentes são negociados a distribuição dos clientes entre eles, a distribuição no mercado vertical, principalmente através da convenção de distribuição exclusiva com proibição de exportação e também com a concessão do auxílio de exportação através de uma Junta.

\subsection{Contrato de distribuição \\ exclusiva}

Entende-se por contrato de distribuição exclusiva os acordos entre fabricantes e comerciantes, através dos quais o fornecedor se obriga a vender a mercadoria somente em uma definida área com a finalidade de revenda exclusiva para um certo comprador.

Entretanto, alguns acordos que procuram uma absoluta defesa do território para o comprador, ou seja, que tem como objetivo o impedimento da importação paralela, infringem o art. 81 (EGV). Desses acordos estão excluídos a proibição da exportação e reimportação de produtos sem garantia originários da importação paralela e o emprego do mercado ou da lei de concorrência desleal.

\subsection{Sistema de distribuição seletiva}

Compreende-se como distribuição seletiva uma organização de venda, na qual o produtor em uma área determinada se limita a só um comprador, que é escolhido por ele. Deste modo, o produtor opta por um comprador de sua preferência e não impõe a este comprador nenhum limite de revenda de mercadoria. Tais organizações são as ligações de comércio especializado simples ou qualificado e distribuição seletiva quantitativa.

A distribuição seletiva quantitativa tem por exemplo um grande significado no setor automobilístico e é regulamentada pelo Decreto ${ }^{\circ} 1.475 / 95$, de 28 de junho de 1995. Previamente vigorava o Decreto $n^{\circ} 123 / 85$, que não satisfez as esperanças da Comissão Européia de finalmente contribuir para a abertura dos, até então, severos mercados nacionais de automóveis, que são caracterizados, como sempre, pela assombrosa diferença de preços (de até $40 \%$ ).

O novo decreto tem em vista a possibilidade da mútua abertura do mercado na União Européia através da restrição das proibições habituais da concorrência por encargo dos comerciantes, como também através da autorização do fornecimento transversal e do intermediário comercial. Deste modo fica incompatível a proteção absoluta da área para o comerciante. Medidas prejudiciais à importação paralela levam à falta de aplicação do Decreto $\mathrm{n}^{\circ}$ $1.475 / 95$, art. 3. Exemplos são o boicote de fornecimento contra sociedades autônomas de leasing ou contra os negociantes industriais intermediários, que comerciam em nome ou por ordem de seus clientes, como também a recusa da prestação de garantia ou do atestado de conformidade para automóvel originário de importação paralela para prejudicar a sua autorização no mercado nacional.

\section{A concorrência desleal}

$\bigcirc \S 1^{\mathrm{o}}$ da Lei contra Concorrência Desleal (UWG - Gesetz gegen den unlauteren Wettbewerb) representa uma abrangente cláusula geral contra a concorrência desleal. $\bigcirc$ combate aos negócios de concorrência desleal e a segurança concorrencial contra as restrições são os dois grandes deveres que uma economia de mercado com oferta e procura pode querer das ordens de direito. No julgamento de uma relação concorrencial percebe-se que faz parte da natureza da concorrência a tentativa de ganhar clientes novos. Todo concorrente procura oferecer e propagar o seu êxito no trabalho sem entraves no mercado para que possibilite ao cliente a comparação das ofertas. Deste modo o cliente pode optar pelo que parece mais vantajoso no preço, qualidade e serviço.

O âmago do preço tabelado é a eliminação da concorrência de preço nas fases de revenda, através do acordo do preço final de venda entre os negociantes e o produtor (§ 15, Lei Anti-Cartel - KartellG). Este corte contratual das possibilidades de concorrência e a tabela de preços que atuam no mercado são, sem dúvida, impertinentes para o negociante. Ou seja, o produtor consegue impor o preço final de venda. Através do contrato de venda com restrições quanto à revenda, são fixadas certas condições para o comprador. Este tipo de acordo aumentou ainda mais, desde que passou a servir como substituto junto com a recomendação de preço, a partir da proibição do preço tabelado para os artigos de marcas conhecidas. Quando um negociante infringir o contrato de venda com restri- ções quanto à revenda ou a tabela de preços, pode o produtor ou qualquer credor exigir, baseado no contrato, um ressarcimento por omissão ou perdas e danos. A inflexibilidade tanto da tabela quanto do contrato restritivo representa para todos um risco, uma vez existindo a possibilidade de reimportação por países que não possuem preços tabelados nem contratos de venda com restrições de revenda. Este perigo vem crescendo desde que o Contrato da Comunidade Européia entrou em vigor, pois o preço tabelado e o contrato de venda com restrições de revenda são proibidos em muitos países membros. Além disso a proibição da reimportação e da reexportação para a proteção do mercado interno infringe o art. 81 do EGV.

Enquanto a reimportação fizer sentido e for de interesse econômico não é possível na Alemanha, por exemplo, a construção de um sistema para a tabela de preços e o contrato de venda com restrições quanto à revenda.

Mas, vale a pena ressaltar, que a inflexibilidade deste sistema tem um significado de lealdade legal para a imposição do direito com relação ao $\S 1^{\text {o }}$ UWG contra compradores que fazem parte de uma Associação e negociantes que não são associados ou ligados a nada.

A importação paralela é permitida dentro da UE em favor do consumidor e da livre concorrência. Normas são determinadas para impedir o abuso de certos privilégios e evitar a concorrência desleal, mas muitas vezes geram o efeito contrário do desejado. 


\section{Bibliografia}

Singer, Ausschießliche Patentlizenz- und Kowhow- Verträge nach deutschem, amerikanischem und europäischem Kartellrecht, 1997.

Hubmann. Götting, Gewerblicher Rechtsschutz, 1998.
Emmerich, Kartellrecht, 1999.

Reich, Europäisches Verbraucherschutzrecht: Binnenmarkt und Verbraucherinteresse, 1993.

Emmerich, Das Recht des unlauteren Wettbewerbs, 1998.

\title{
O Poder Judiciário e a Concretização das Cláusulas Gerais: Limites e Responsabilidade*
}

\author{
Ruy Rosado de eAguiax fuiniox \\ Ministro do Superior Tribunal de Justiça.
}

\section{1a Parte}

(1) bilidade".

ma que me foi proposto é: "O Poder Judiciário e a concretização das cláusulas gerais: limites e responsa-

Quero iniciar falando sobre o significado da concretização das cláusulas gerais dentro da atividade estatal.

Sabemos todos que a forma de atuação do Estado na economia tem sofrido variações que vão desde o absenteísmo do Estado mínimo ao Estado Intervencionista.

A partir da Revolução Francesa, observa-se acentuada tendência de intervenção na forma de direção, proteção ou de participação, variando as suas modalidades ou o seu ritmo conforme o país.

Embora se diga que na pós. modernidade o Estado deve estar cada vez mais ausente, a verdade é que ele dirige a economia.
Nos EEUU - símbolo do liberalismo - o agricultor planta aquilo que o Estado quer, não planta o que o Estado não quer; tem preço mínimo para o seu produto e re. cebe garantia de indenização pelo que não lhe foi permitido plantar.

Nos países neoliberais, a economia continua sendo presidida e orientada pelo Estado. Em um que nós conhecemos, essa direção se dá através de inúmeras medidas provisórias e resoluções de um ou de outro órgão governamental, além de atuação concreta no mercado financeiro.

Pois bem, na medida em que se faz presente o Estado no processo econômico, uma das áreas mais atingidas é o contrato.

O Prof. EROS GRAU acentuou que no regime ocidental capitalista em que vivemos, a sociedade está fundada em dois pilares: na idéia da propriedade privada dos bens de produção e na da liberdade de contratar, que é o seu corolário mais importan- 